\title{
Child or Grown-up: Language Universals and Language Particula
}

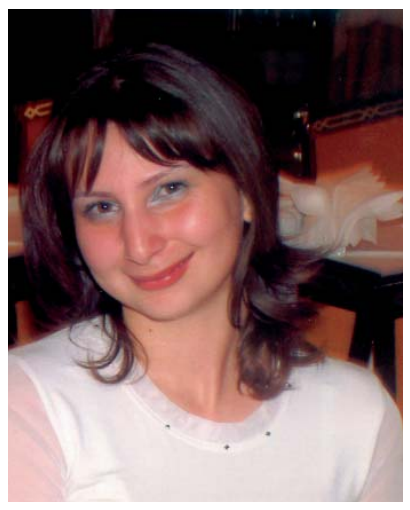

Rouzanna Arakelyan anguage is a unique defining property of our
humanity. The ability to acquire language has
become a very interesting, yet controversial field of study.
How children and adults master not only their first, but
also a second language is the subject of ongoing research.
Although every child, regardless of intellectual level, is
equally gifted at acquiring the native language, it does not
seem to be the case with adults. Some adults can learn a
second language with something close to native fluency;
others will retain a distinct foreign accent even after
decades of practice.

The age at which individuals should be exposed to a second language has also been a long standing topic of discussion among researchers, educators and learners. The cause for this interest is manifold, relating also to theoretical issues, such as whether an innate language faculty continues to function beyond a particular point of maturation. The age and maturation of the individual seem to be the crucial factors in any language acquisition, as before puberty a person acquires language naturally, while the same person before puberty acquires it with great effort that yields less than perfect results.

The reason why the sharp disparity between the so-called "unexceptional success" of normal children and the general lack of success of adults may strike us as paradoxical at first may have something to do with our common sense. It is easy to see that every child is a wonderfully unique and special individual, different in many ways from other children living and that at least some of the differences are environmental. But it is no less true that, in a deeper sense, every child is like every other child, and that they all go through the same highly predictable stages.

It is really not hard to see that children develop in a patterned way, so the following four basic stages can be mapped in the childhood path. The first goes from birth to about two years of age and one of its defining features appears to be 'out of sight, out of mind'. In the second stage, from two to seven years, children are quite sophisticated talkers, even emerging readers, as language is already in its essential place. In the third stage, roughly from seven to twelve years, 'the age of reason', numbers and logic are no longer arcane. Finally, in the fourth stage, which starts after the age of twelve or so, abstract reasoning, including the possibility of investigating all aspects of a problem systematically is well within reach. ${ }^{1}$

The idea that non-native language acquisition is in some important respect not unlike 
first language acquisition does not lack antecedents in the research area. Some of the best investigations in language acquisition after puberty, more precisely after the maturational stage associated with the development of a first language, have concluded that adults, as a rule, fail to achieve native-speaker competence in a new language, whereas children seem to be generally able to develop full command of either a first or a second language as a product of maturation.

This inability of the postpubescent adult to attain the kind of achievement invariably attained by children comes as no surprise to those who take the Critical Period Hypothesis seriously, assuming essential differences in the capacity for language of child and adult because of genetically determined changes in the maturing organism. In the Critical Period Hypothesis /CPH/, there is a neurologically based period ending around the age of twelve, beyond which complete mastery of a second language acquisition is no longer possible. During this period, the dominant hemispheric is more specialized for language. This process of interhemispheric specialization is responsible for acquiring the language and not having a foreign accent. In addition, there is a process of further specification of a particular language function in specific areas of the dominant hemispheric that is more specialized for language. This process of interhemispheric specialization, which leads to the loss of cerebral plasticity remains for those functions not yet localized. It may suggest that there is not one but many critical periods, lasting probably through one's lifetime, each closing off different acquisition abilities. These are determined by the differential recovery patterns from right and left hemisphere lesions at different ages. Lennenberg, the founder of the Critical Period Hypothesis, states that while acquisition of a behaviour outside the period in which it normally occurs is not impossible, it will proceed by a different route and will generally be less successful and natural. ${ }^{2}$

Taking into account these facts, one could suppose that the diminution of child-like language acquisition skills and the phenomena of onset of adult sexual characteristics are interdependent, as it is believed that some change in the structure of the brain that occurs at puberty does reduce language learning ability. This is actually "the consequence of an evolutionary adaptation", as the brain is a "greedy" organ and is using much energy. Thus, it can be assumed, that a larger portion of the neural capacity in a child's brain is aimed to take a part in the acquisition of languages.

Initially, the notion of a critical period was connected only to first language acquisition. Today, the "classic" argument is that a critical point for second language acquisition occurs around puberty, beyond which people seem to be "over the hill", when it comes to the possibility of a nativelike accent of the second language. Proponents of the $\mathrm{CPH}$ are inclined to think that children before puberty are good phoneticians, whereas adolescents and adults are often good grammarians and semanticians.

In order to examine all these issues related to the psycholinguistic aspects of language acquisition more closely, we should look at neurological and psychomotor, cognitive and linguistic considerations more carefully. As for the neurological evidence, research suggests that as the human brain matures, certain functions are assigned or 
"lateralized". Thus, intellectual, logical, analytical and language functions appear to be largely located in the left hemisphere, whereas the right hemisphere controls functions related to emotional and social needs. While questions about how language is lateralized in the brain are interesting indeed, a more crucial question for second language researchers has centered on when lateralization takes place, and how it affects language acquisition. Lateralization is a slow process that begins around the age of 2 and is completed around puberty. During this time, the child neurologically assigns functions to either one side of the brain or the other. Cognitive considerations suggest that human cognition developes rapidly throughout the first 16 years of life and less rapidly after adulthood. Some of these changes are critical, others are more gradual and difficult to detect.

It should be stated that the lateralization hypothesis may provide another key to cognitive differences between child and adult language acquisition. As the child matures into adulthood, the left hemisphere (which controls the analytical and intellectual functions) becomes more dominant than the right hemisphere (which controls the emotional functions). In examining the cognitive domain of language acquisition the Piagetian notion of equilibration ${ }^{3}$, should also be considered. Equilibration is related to the concept that cognition develops as a process of moving from the states of doubt and uncertainty (disequilibrium) to the stages of resolution and certainty (equilibrium) and then back to further doubt that is, in time, also resolved. And so the cycle continues. It is conceivable that disequilibrium may provide the key motivation for language acquisition, that is language interacts with cognition to achieve equilibrium.

Children learning two languages simultaneously acquire them by the use of similar strategies. They are, in essence, learning two languages, and the key to success is in distinguishing separate contexts for two languages. For the most part, research confirms that the linguistic and cognitive processes of second language learning in children are generally similar to first language processes. Adults, more cognitively secure, appear to operate from the solid foundation of the first language and, thus, manifest more interference. Views such as these are rather consistent with more recent experimental work that has got some theoretical implications. For instance, in their discussion of critical period effects in learning a second language, Johnson and Newport conclude that the decline in that process begins far beyond puberty, even before the threshold of fifteen years of age, as the other researcher Patkowsky found out later. ${ }^{4}$ In response to these and many other empirical studies, Long, reviewing the second language research on agerelated differences, has drawn conclusions that are relevant to this topic: a) both the initial rate of acquisition and the ultimate level of attainment depend in part on the age at which learning begins; b) there are sensitive periods governing both first and second language development, during which the acquisition of different linguistic domains is successful and after which it is incomplete. ${ }^{5}$

This analysis is actually an attempt to show that there is no reason to doubt the validity of the above mentioned position. The biological fact of adulthood appears to be enough to establish an insurmountable obstacle to nativeness in a new language, which is assumed to have physiological and cognitive bases. This does not mean, of course, 
that no language acquisition is possible after a certain age or that other factors, such as methods of instruction or affective elements like attitude and motivation, cannot contribute to determining varying degrees of proficiency in one or more foreign languages. It does not mean either that there is no point in taking into account the knowledge of universal principles of grammar that constrain language development in the maturing child as a necessary framework for the investigation of foreign language acquisition.

If the burden of explanation is placed on the environment, there is every reason to expect adults to do even better than children. In contrast to this, today it is widely understood that part of the explanation can only be provided by the conception that a language exists only in the brain of an individual and should be studied in an individual psychology setting.

The conclusion that a foreign language can be acquired only through persistent study, and that a teaching program can only provide valuable, but never sufficient help, is neither negative, nor pessimistic. A high level of success on the part of the student, after a considerable amount of effort, is in some way a greater individual achievement than becoming a native speaker in childhood. The challenge posed by a relative mastery of a foreign language, involving will and deliberate choice, is met with a high degree of success only by those with determination to attain it. Moreover, to come to know a foreign language is an extraordinary intellectual achievement for a brain not specifically designed to acquire a language after puberty. This is when a child needs specific training and negative evidence /correction/. Still, relative mastery of a foreign language appears to go even a step further than relative mastery of, say, mathematics or physics through conscious effort. In the case of a foreign language, conscious language is at most a first step, since there is little reason to believe that a person could consciously master grammar as a guide to verbal behaviour.

The thesis that only some invariant principles of the language organ remain active after the critical period appears to be a highly reasonable one, with strong empirical research to support it. It seems a fair guess that stronger evidence is obtainable and will perhaps be made available in the non-distant future. The sharp contrast between the child and the adult on this score also suggests that the data from language acquisition after puberty will provide a new kind of evidence for the study of language in general.

\section{References:}

1. Пиаже Ж. Речь и мышление ребенка. 1994, Москва, стр. 24

2. Lennenberg, E. “Biological Foundations of Language. New York: John Wiley and Sons. 1981, pp.59-63

3. Rod Ellis “SLA Research and Teaching”. 1997, Oxford University Press, p.11

4. Johnson J.S. and Newport E. "Critical Period Effects on Universal Properties of Languages: the Status of Subjacency in the Acquisition of a Second Language”, Mass., 1989, p.58 
5. Long, M. "Maturational Constraints on Language Learning”. Studies in Second Language Acquisition. Mass., 1990, p.251

\section{Ltiquh jnıpmgruma huúnginhmanıp le mahmunmuma huunluahzating}

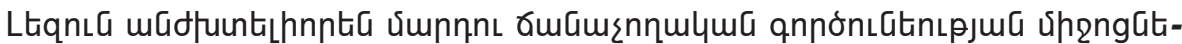

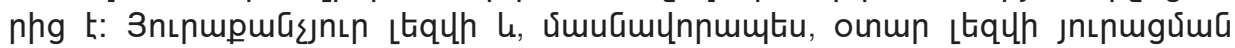

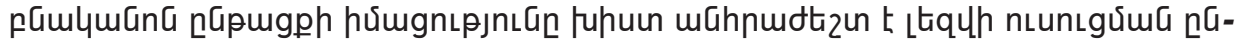

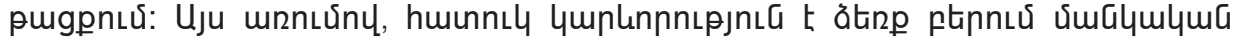

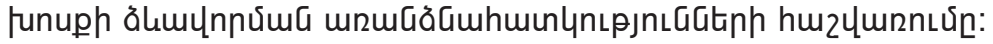

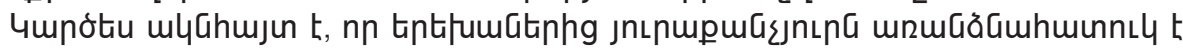

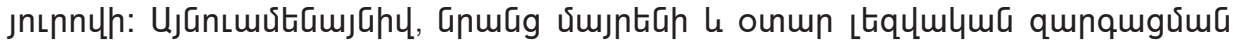

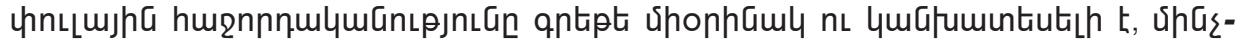

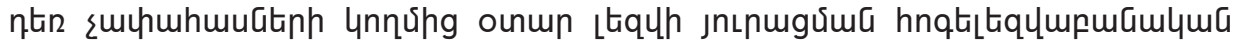

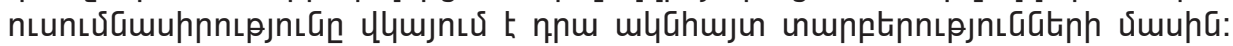

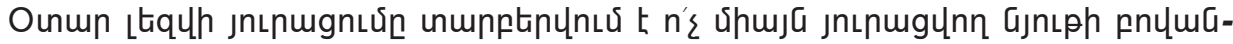

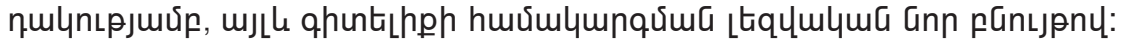

